\title{
Soil-structure interaction analysis considering concrete creep and shrinkage
}

\section{Interação solo-estrutura: análise contemplando fluência e retração do concreto}
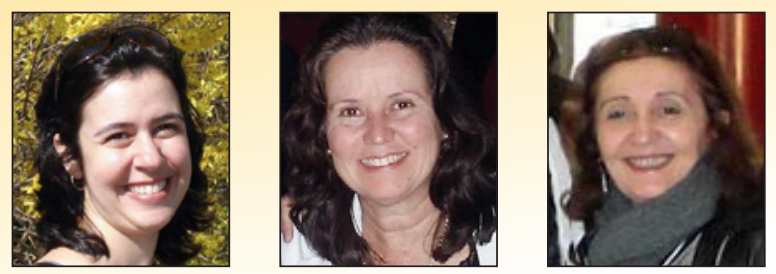

L. M. P. ROSA

lucianamprosa@gmail.com

B. R. DANZIGER b bernadeterd@hotmail.com

E. M. L. CARVALHO elianemaria55@gmail.com

\begin{abstract}
The paper presents some results from Rosa's [1] research that aimed to verify the effect of creep and shrinkage of the concrete in soil-structure interaction. The construction consists in a 17 storeys building. It is set down on shallow foundation, in the central part of the construction, and steel piles, on the boundary. The structure was submitted to instrumentation during construction, including the monitoring of foundation settlements and columns deformation. It was possible to compare the structural design with a numerical refined structural analysis. Comparisons of the structural and foundation design with and without due consideration of soil-structure interaction are also presented. Finally, the different design assumptions were confronted with instrumentation results, both related to foundation settlements and to columns loading as well. Attention is pointed out on the effect of concrete creep and shrinkage in the soil-structure interaction analysis.
\end{abstract}

Keywords: soil-structure interaction, foundation settlements, instrumentation.

\section{Resumo}

O presente artigo apresenta alguns resultados da pesquisa de Rosa [1], que teve por objetivo verificar o efeito da fluência e retração do concreto na interação solo-estrutura. Foi analisada uma edificação com 17 pavimentos mais subsolo, em fundação mista, submetida à instrumentação de campo contemplando o monitoramento de recalques e deformação de alguns pilares, ao longo do processo construtivo. Foi possível comparar o projeto do calculista com uma análise numérica mais refinada. Também se comparou o projeto, sem considerar e considerando a interação solo-estrutura. Finalmente, os diferentes cenários de projeto foram confrontados com os resultados experimentais, tanto em relação aos recalques como aos esforços nos pilares instrumentados. Atenção particular foi dada ao efeito da consideração da fluência e retração do concreto na análise da interação solo-estrutura.

Palavras-chave: interação solo-estrutura, recalque, instrumentação. 


\section{Introduction}

In section 5.5 of the last review of ABNT NBR 6122 [2] Foundation Rule, it is recommended that "In structures where the deformability of foundations can influence the distribution of stresses, the soilstructure interaction or foundation-structure interaction must be considered in design".

In the case of structures settled on mixed foundations, which are those including some columns founded on shallow foundation and other columns resting on deep foundation, the soil-structure interaction assumes a relevant premise in design. In fact, in mixed foundation the heavily loaded central columns are commonly founded on shallow footings with a high contact area with the soil mass and the less loaded peripheral columns are founded on piles. The pile settlement is commonly much smaller than the settlement of the shallow foundation. The deformability of the foundation soil can significantly influence the distribution of stresses. In accordance to the Brazilian Standards, this kind of project should also include a soil-structure interaction analysis, an issue that is not commonly considered in current practice.

This paper includes part of Rosa's doctoral research [1] consisting of the analysis of a building in mixed foundations submitted to settlement instrumentation and monitoring of the stresses and the deformation of some columns during the complete construction process. A settlement prediction is made for various construction stages. The settlements magnitude and its distribution in the foundation plant were estimated based on a consistent soil model. A detailed structural model for the structure was also considered.

The structural analysis has been performed with the aid of a threedimensional elastic model of the structure, using a program based on the finite element method (MEF). Due to the consistent soil and structural model adopted in design, it was possible to establish a comparison of the predicted and the measured behavior of the soil structure interaction.

The results of the soil-structure interaction analyses for the different construction stages were interpreted. The effects of creep and shrinkage of the concrete on soil-structure interaction have also been interpreted.

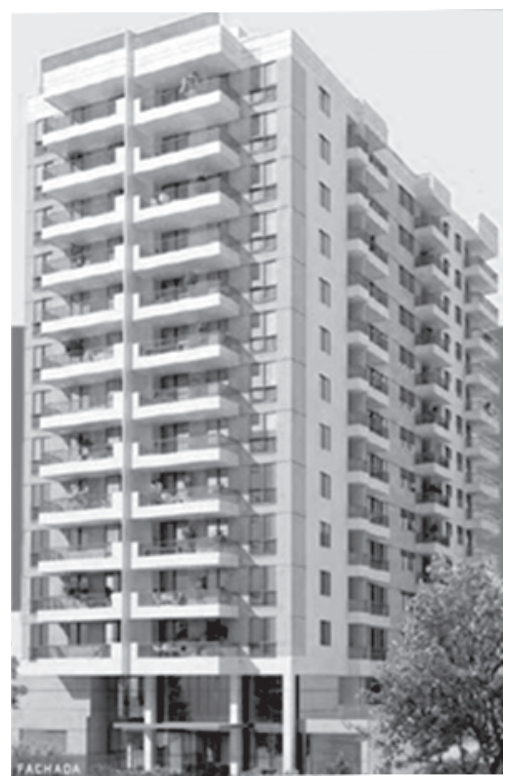

Figure 1

Building frontal view

\section{Soil characterization and structure description}

The structure consists in a residential building located in Niterói, RJ, with 12 floors, a roof, a first floor of common use, the ground floor, a semi-underground floor and the underground, shown in Figure 1. The structure is in reinforced concrete with a conventional geometry, resting on mixed foundations (Figure 2 (a)). Part of the columns is founded on deep foundation consisting in steel driven piles and part of the columns is founded on footings.

The geotechnical profile is shown in Figure 2 (b). The soil profile indicates a sedimentary uniform deposit, consisting of a landfill on its surface, with a thickness of approximately 0.7 meters in almost all borings. Bellow the landfill, a layer of sandy clay is observed, with a thickness varying between 1 and 2 meters. The sandy clay layer over-

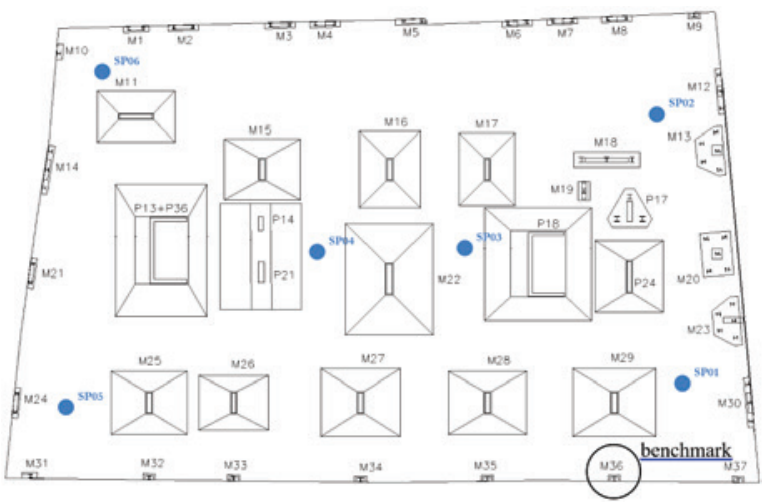

A

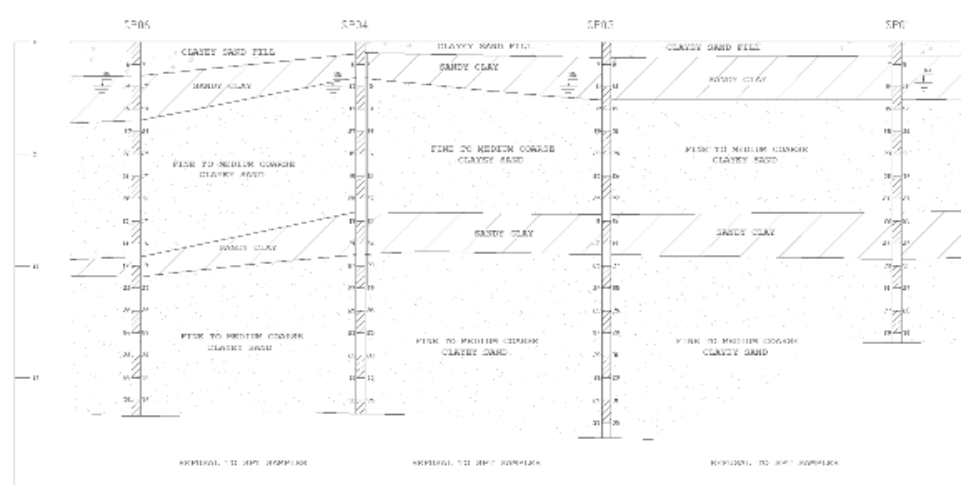

B

Figure 2

(a) Foundation plan; (b) Geotechnical profile 
lies a layer of thin, medium and coarse clayey sand, with a thickness ranging from 5 and 8 meters. These two layers, in turn, are laid on another layer of sandy clay, with a thickness of approximately 2 meters. Finally, another layer of fine, medium and coarse sand, with a variable thickness occurs up to the depth of SPT sampler refusal, where the borings were interrupted. The water level is about $2 \mathrm{~m}$ below ground level in the boring logs. The location of the SPT borings is also shown in Figure 2 (a).

The shallow foundations are embedded into a depth of $-4.65 \mathrm{~m}$ from the ground level, except for P13 + P36, P14 + P21, M15, M16, M17, M22, P18 and P24 columns, whose foundation rest at $-6.52 \mathrm{~m}$ depth. The ground level at the time of the soil borings is considered as the reference level. All the shallow foundations are embedded into a sandy soil layer of medium density. According to the project data, an allowable soil stress of $0.4 \mathrm{MPa}$ was considered in the foundation design. The $\mathrm{H}$ shaped steel piles had length ranging from $14 \mathrm{~m}$ to $23.4 \mathrm{~m}$.

\section{Structural model}

From the building's plants, a three-dimensional structural model in finite elements was conceived with the aid of the SAP2000 commercial program. The beams and columns were modeled as bar elements and the slabs and the structural wall as plate elements as shown in Figure 3.

Different models were created for the structure analysis. The first model considered the structure founded on rigid supports and its main purpose was to compare the column loads obtained in the numerical analyses with the loads estimated from the original design. Differences found in the loads magnitude were close to $3 \%$. Such small difference is due to the fairly regular geometry of the building itself and the conventional conception of the structural model.

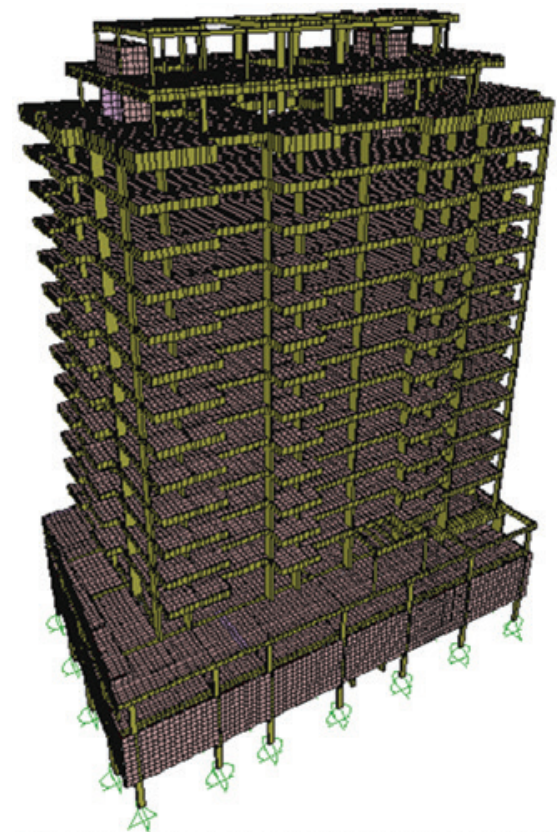

Figure 3

Numerical model of the building under study

\section{The field instrumentation}

The construction started in early 2011 and field observation initiated in July 2011 . Six constructive steps including the instrumentation of some columns were monitored between November 2011 and June 2012. The instrumentation is detailed in the next section. The field instrumentation aimed to monitor the settlement and deformation of the columns over time. Measurements were taken at various construction stages.

The settlement measurements involved the development of a precise optical leveling based on a deep reference, considered at a fixed point of the structure with insignificant predicted settlement in view of the estimated settlement of the most heavily loaded columns on shallow foundation. Stainless steel pins were installed on the external faces of 11 columns of the structure on the underground floor, at a height of approximately $30 \mathrm{~cm}$ above the floor. The procedure for settlement measurement consisted basically of leveling the column pins in relation to an external fixed reference, called "benchmark". The benchmark is commonly installed in a place protected against any external and internal cause that may interfere or have some influence on the actual measurements. The benchmark is also shown in Figure 2 (a). The pins served as support for the ruler. With periodic leveling, it was possible to obtain the settlements in different phases of loading and construction of the building.

In the specific case of this construction, it was not possible to select an external reference, since there was no external point, placed anywhere externally and in the surroundings, visualized from the building site, where it would be guarantee of not presenting any movement at all. In addition, the research team had not enough financial support to provide a benchmark internally to the construction site. Then it was decided to select an internal column as a reference. The reference column was selected as the one with

Figure 4

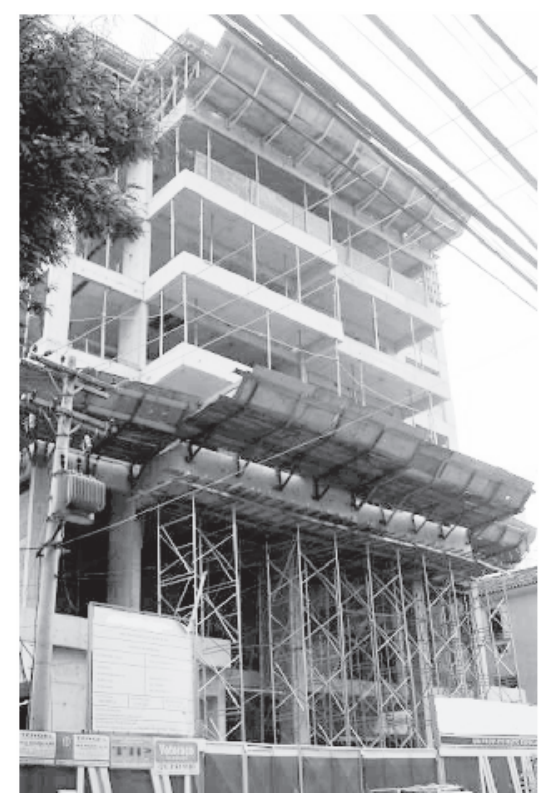

Construction aspect at the second construction stage 
Table 1

Construction stages

\begin{tabular}{|c|c|c|}
\hline Model & Construction stage & Time (days) \\
\hline Start & - & 0 \\
\hline $1^{\text {st }}$ reading & Structure built up to the $4^{\text {th }}$ floor & 203 \\
\hline $2^{\text {nd }}$ reading & Structure built up to the $5^{\text {th }}$ floor & 217 \\
\hline $3^{\text {rd }}$ reading & $\begin{array}{l}\text { Structure built up to the } 9^{\text {th }} \text { floor, } \\
\text { masonary concluded up to the } \\
\qquad 4^{\text {th }} \text { floor }\end{array}$ & 266 \\
\hline $4^{\text {th }}$ reading & $\begin{array}{c}\text { Structure built up to the cover } \\
\text { ceiling, masonary concluded up to } \\
\text { the } 10^{\text {th }} \text { floor, wall coverings finished } \\
\text { up to the } 2^{\text {nd }} \text { floor }\end{array}$ & 310 \\
\hline $5^{\text {th }}$ reading & $\begin{array}{l}\text { Structure finished, masonary } \\
\text { concluded up to the } 11^{\text {th }} \text { floor and } \\
\text { wall covering finished up to the 3rd } \\
\text { floor }\end{array}$ & 336 \\
\hline $6^{\text {th }}$ reading & $\begin{array}{l}\text { Structure finished, masonary } \\
\text { concluded and wall covering } \\
\text { finished up to the } 7^{\text {th }} \text { floor }\end{array}$ & 413 \\
\hline
\end{tabular}

estimated settlement much lower than any other column that would be instrumented in the construction site.

Settlement measurements were carried out in 6 constructive steps. Figure 4 shows the construction stage of the building at the $2^{\text {nd }}$ measurement stage, in December 2011.

It is noteworthy to emphasize that the first measurement occurred with the construction built up to the fourth floor. Thus, the first instrumented stage will be considered as the "zero" reading and the other measurements based on this reference.

\section{Table 2}

Instrumented columns and foundation type

\begin{tabular}{|c|c|}
\hline Columns* & Foundation type \\
\hline M15 & Shallow \\
\hline M20 & Deep \\
\hline M21 & Deep \\
\hline M22 & Shallow \\
\hline M23 & Deep \\
\hline M25 & Shallow \\
\hline M28 & Shallow \\
\hline M29 & Deep \\
\hline M32 & Deep (reference) \\
\hline M36 & Shallow \\
\hline P13+ P36 & Shallow \\
\hline P18 & Shallow \\
\hline P24 & 4 \\
\hline *(For columns location, see Figure 2(a)) & \\
\hline
\end{tabular}

For each stage with measured settlements, a corresponding structural model was conceived, with actual loads corresponding to this particular construction stage. Table 1 indicates the constructive stages in which the measurements were made and the date when they took place. Table 2 lists the instrumented columns submitted to settlement monitoring and the type of foundation, whose location are indicated in Figure 2 (a).

Figure 5 shows the curves of settlements distribution for the $6^{\text {th }}$ and last instrumented step. The curves join the points, in a plan-view, interpolated from the measured settlements. At this $6^{\text {th }}$ stage the structure and masonry of the whole building was already completed and and wall covering finished up to the seventh floor.

It was observed that the largest settlements occurred in the columns supported on shallow foundations. Much lower values have

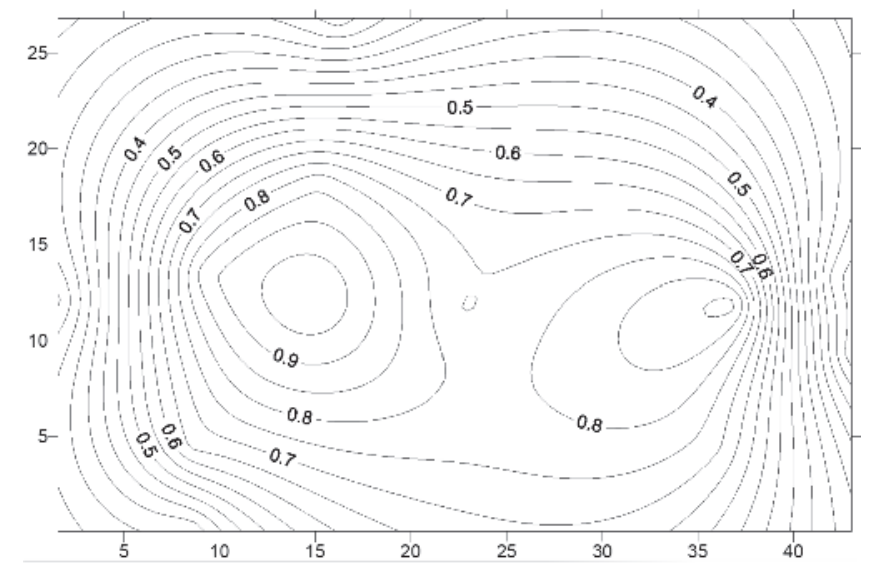

Figure 5

Measured settlements distribution curve for the 6th construction stage, values in centimeter 


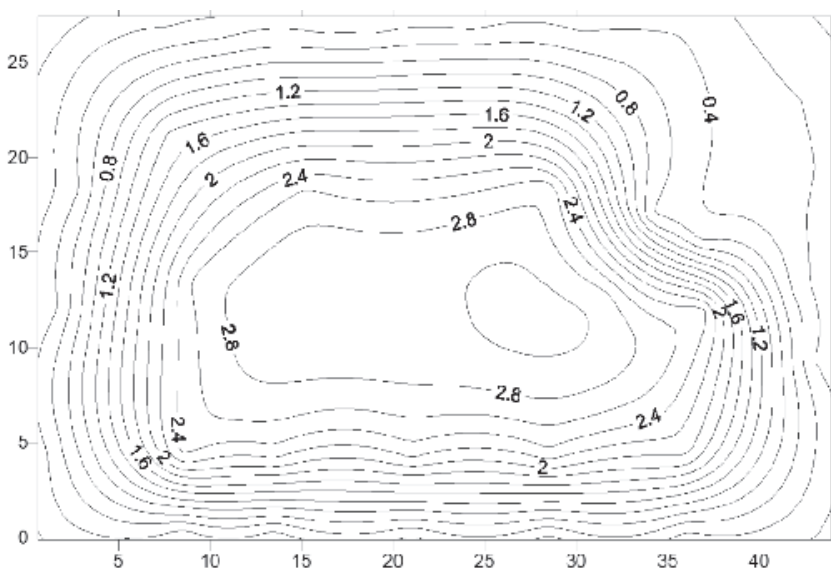

Figure 6

Estimated settlements distribution curve for the complete structure according to original design, values in centimeter

been observed for the columns supported by steel piles driven into high resistance soils, as expected.

In all the stages with instrumented settlements the registers of columns deformation were also carried out. Besides the settlement and columns deformation registers, the environmental temperature and the humidity present in the air were also measured by the use of a thermo-hygrometer. There was no significant variation in the measurements of temperature and air humidity. The mean values measured were 27 degrees Celsius, for the temperature, and $75 \%$ for the degree of moisture in the air. These values have been considered in the analyses considering the creep and shrinkage that will be presented in section 6.3 .

\section{Settlement prediction}

The method of Aoki and Lopes [3] was adopted for settlement estimation. The method calculates tensions and settlements inside the soil mass caused by a group of loads transmitted from piles and footings to the foundation soil. The transmitted loads are decomposed into an equivalent system of concentrated loads, whose effects are superimposed at the points under study.

Based on a computational program developed by Aoki-Lopes [3] the settlements caused by the whole group of the column loads were estimated.

It is important to note that these values were calculated with the main purpose of checking the locations with the larger and lower settlement in the foundation plan and to have an idea of the order of magnitude of the estimated settlements.

Figure 6 shows the estimated curves of settlements distribution for the design loads, with no consideration of soil-structure interaction. Note that for the columns resting in deep foundation the settlement presented much smaller values compared to those columns resting on footings. The highest settlement values occurred for the central columns. The lower settlement values occurred for the columns positioned at the building periphery, with deep foundation. It should be noted that the settlements measurements started with the reinforced concrete finished up to the 4 th floor. The estimated settlements in Figure 6 consider the complete structure and for the loads calculated in the original design.

\section{Structural analyses}

\subsection{Numerical models}

A structural model was conceived for each instrumented stage of the construction process. It was possible then to compare, for each stage, the measured loadings with those calculated from the numerical analysis for each construction phase.

In a preliminary phase of the numerical analysis, the loads were applied to the model for each construction stage considering the dead loads transferred from the columns to rigid support. The settlements were then estimated considering the loads obtained in each numerical model relative to each constructive stage. The Aoki-Lopes [3] method was adopted.

In the subsequent phases of the analysis the supports did allow to present vertical settlements. Since the footings rest in a sandy layer, characterized by a rapid compressibility, the model conceived to represent the soil behavior was composed by linear springs. The soil spring stiffness values were estimated from the loads transmitted to the foundations and the respective calculated settlement. This procedure was followed for all the construction stages, in order to reproduce the compressibility of the sand layer during the whole construction.

The estimation of the stiffness coefficients of the representative springs of the soil model was based on the definition of the coefficient of soil reaction, represented by $\mathrm{K}$, which is the ratio of the working load and the settlement, expressed in $\mathrm{kN} / \mathrm{m}$.

The values of the stiffness coefficients, estimated as explained above, were considered as a boundary condition in the structural model for the following iteration. Several iterations were made for each numerical model up to the convergence of successive stiffness values. The convergence was observed after 3 iterations.

\subsection{Calculated settlements compared to measured settlements}

From the numerical models conceived for each construction stage, it was possible to compare the measured settlements with the estimated settlements. Figures 7 (a), 7 (b), 7 (c) and 7 (d) show the estimated settlement distribution curves for the $6^{\text {th }}$ construction stage, considering rigid supports, Figure 7 (a), and considering each of the successive 3 iterations calculated with soil-structure interaction, respectively.

It can be observed that the largest settlements are estimated for the model loads relative to the rigid support. After the introduction of the soil-structure interaction effect in the analysis, there is an evident change in the position in plan of the largest settlements. On the other hand, the difference is not very clearly observed in the settlement distribution when a much degree of refinement is incorporated in the analyses (higher number of iterations), until settlement convergence is attained. The complete and detailed results can be better followed in Rosa's research [1].

It was also verified that these multiple iterations analyses are very laborious and do not result in significant differences in the 
settlement behavior in the several iterations besides the first, when considering the soil structure interaction effect. No significative difference was observed in the settlement distribution in plan and no relevant difference was also noted in the load foundation redistribution, after the first iteration. Since the foundation represents the last phase of the project and the first of the construction, the authors consider that for current projects, with short deadline, the analysis of the soil structure interaction can be justified in one single iteration analysis.

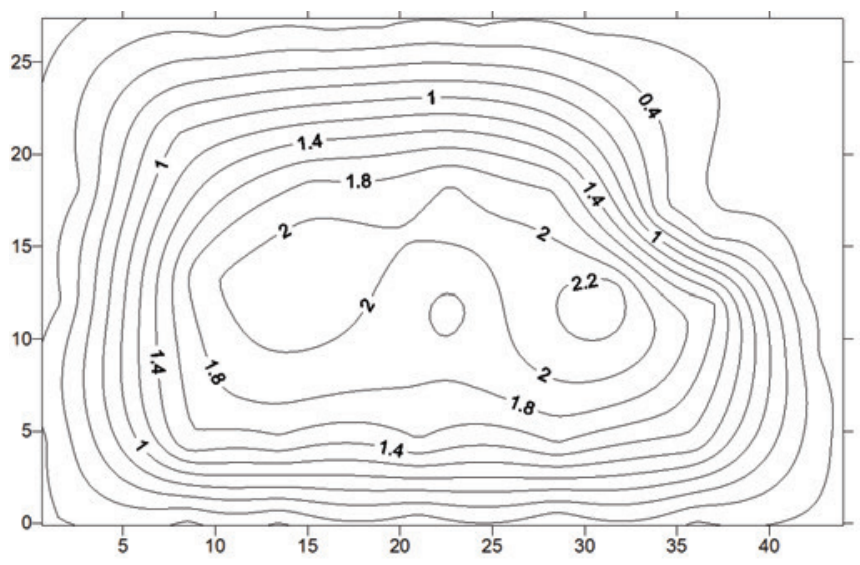

A Estimated, rigid supports
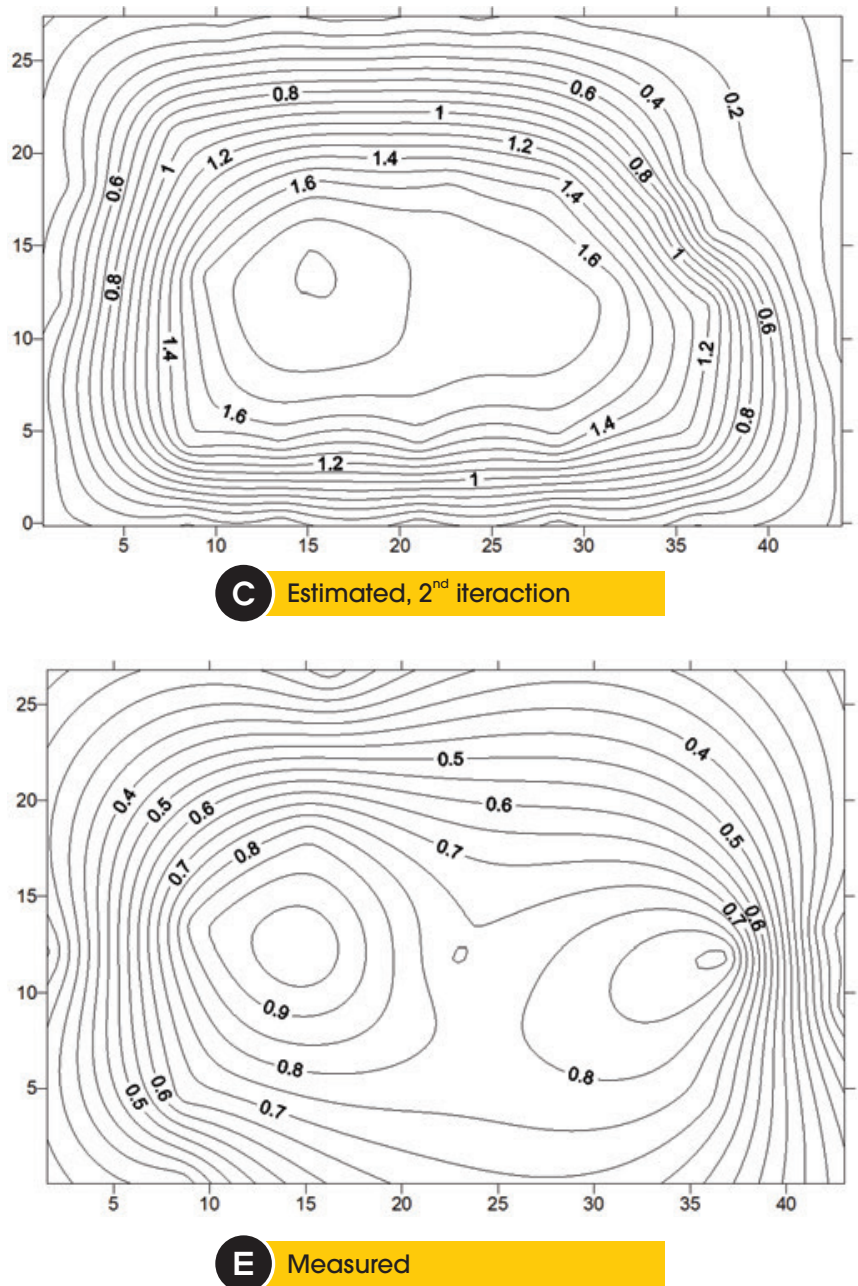

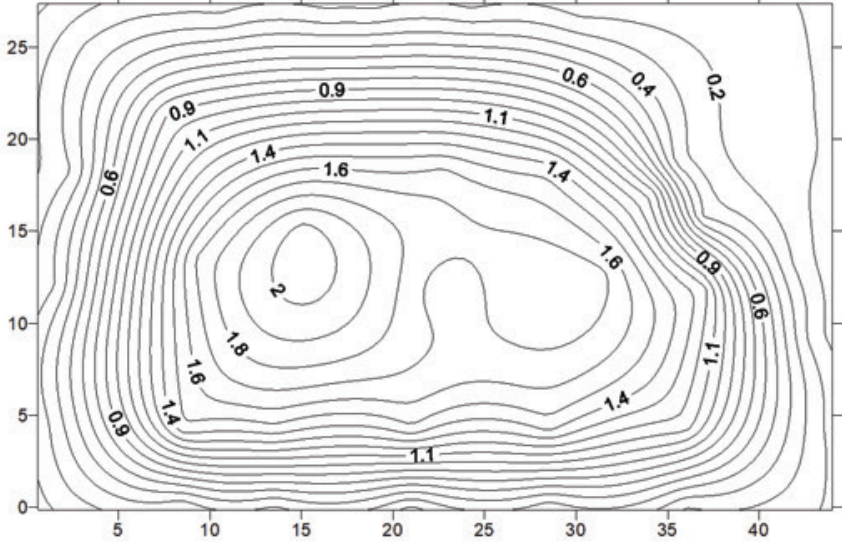

B Estimated, $1^{\text {st }}$ iteraction

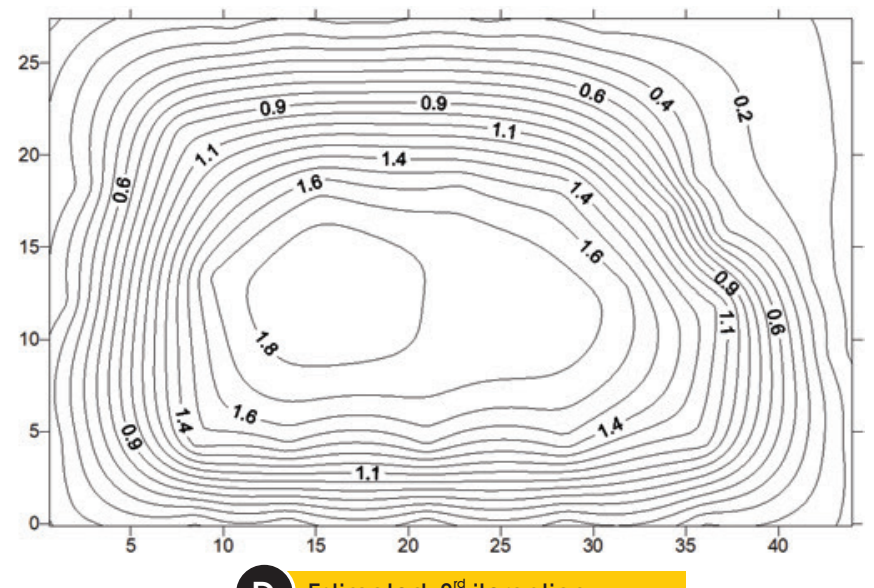

D Estimated, $3^{\text {rd }}$ iteraction

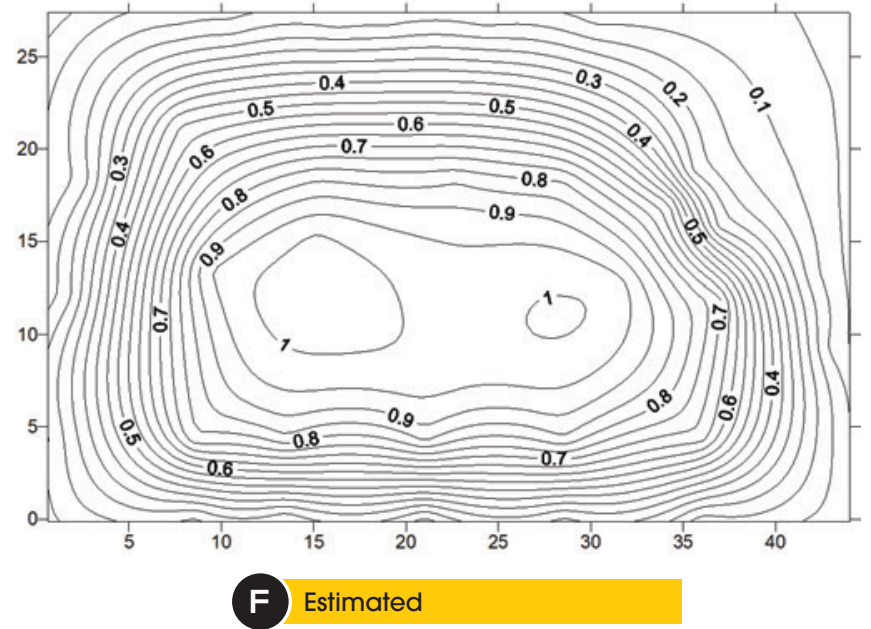

Figure 7

Settlements distribution curves for the $6^{\text {th }}$ stage, values in centimeters 
The proceeding analyses performed by Rosa [1] compare the estimated settlement distribution to the measured settlement distribution. This comparison aimed at the evaluation of the estimated compressibility parameters of the soil mass and the ability of the Aoki-Lopes method to predict the measured settlements satisfactorily. It should be pointed out that although the Aoki-Lopes method [3] has been originally conceived for deep foundations, it can also be used for shallow and mixed foundations, as in the present case. For the $6^{\text {th }}$ construction stage, the measured values are illustrated in Figure 7 (e) and predicted settlements in Figure 7 (f). Once the measurements initiated after the beginning of the construction, the calculated settlements correspondent to the loads acting up to the start of the instrumentation were reduced from the total calculated settlement. Those are the settlement shown in Figure 7 (f).

It can be observed that Figures 7 (e) and 7 (f) are similar, with higher settlements of $1 \mathrm{~cm}$, in the central part of the building, especially in the locations where the columns are founded on footings. In the part of the foundation plan with preponderance of deep foundation much smaller settlements were observed.

The similarity in the settlements values indicates the suitability of the soil compressibility model, which had already been observed by Conde de Freitas et al [4]. The similarity of the settlement distribution between curves Figures 7 (e) and 7 (f) reveals the adequacy of the numerical model to reproduce soil structure interaction behavior.

It is worth recalling the effect of the construction sequence on the soil $x$ structure interaction observed by Gusmão Filho [5] and illustrated in Figure 8. Figure 8 shows the increase in settlement with the progress of the construction stages. At the same time the increase in the average settlement is observed, due to the increase of the loading, the variability of the settlement decreases. In fact, the coefficient of variation of the settlement tends to decrease with the advance of the construction due to the interaction effect.

Figures 9 (a), 9 (b) and 9 (c) illustrate this same effect for the building under study. Since settlement instrumentation did not start at the beginning of construction, the statistical values (mean, standard deviation and coefficient of variation) were calculated adding to the measured settlement the value of settlement estimated for the loading correspondent to the initial of the instrumentation. Calculated settlements were taken from the beginning of construction. Figures 9 (a), 9 (b) and 9 (c) illustrate, respectively, the mean, standard deviation and coefficient of variation of the estimated and the measured settlements. The calculation of the mean was made considering the sum of the settlements in each instrumented column divided by the number of columns (11), for each of the instrumented stage (6 stages). The standard deviation and coefficient of variation, which is the ratio of the standard deviation to the mean, were also calculated and shown in the figure.

It is observed that the mean measured settlement is practically coincident with the mean estimated settlement, except for the interval of 310 days from the beginning of the instrumentation, precisely at the time when 3 readings were lost. Possibly, the reduction in the number of observations resulted in the impairment of the mean instrumented settlement value. Otherwise, it was also observed that the mean calculated settlement, in the same interval (310 days), which included the average of 11 values, approached much closer to the overall trend, compared to the measured settlement curve at this same interval, whose mean moved apart from the overall behavior.

The measured standard deviation values were also very close to the calculated values, except for the reading corresponding to the same interval (310 days), precisely the same interval when 3 readings were lost. Possibly, impairment of the mean value resulted in the same effect on standard deviation. However, while the mean estimated settlement has approached to the overall trend, the standard deviation did not follow the same tendency. No reason for such an outcome has yet been identified.

Once the measured settlements at the beginning of the instrumentation were considered the same as that estimated, the curve representing the mean, the standard deviation and the coefficient of
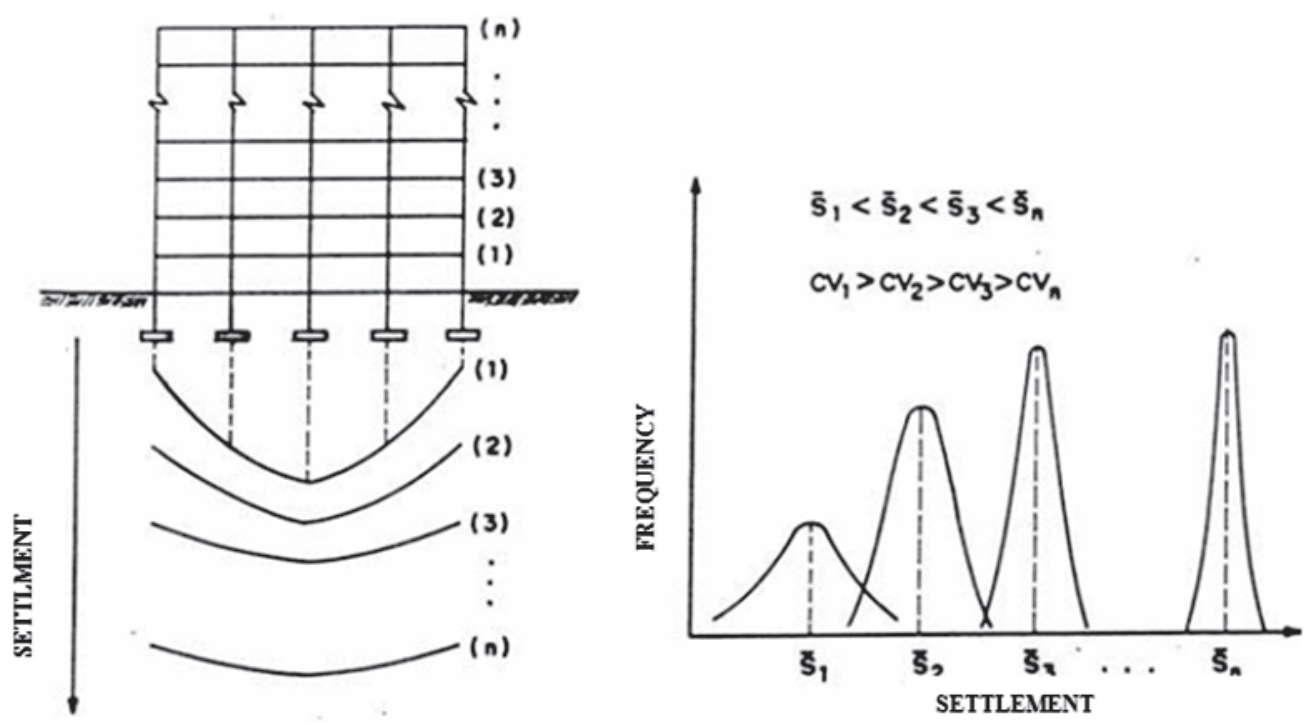

Figure 8

Effect of construction sequence, Gusmão Filho [5] 

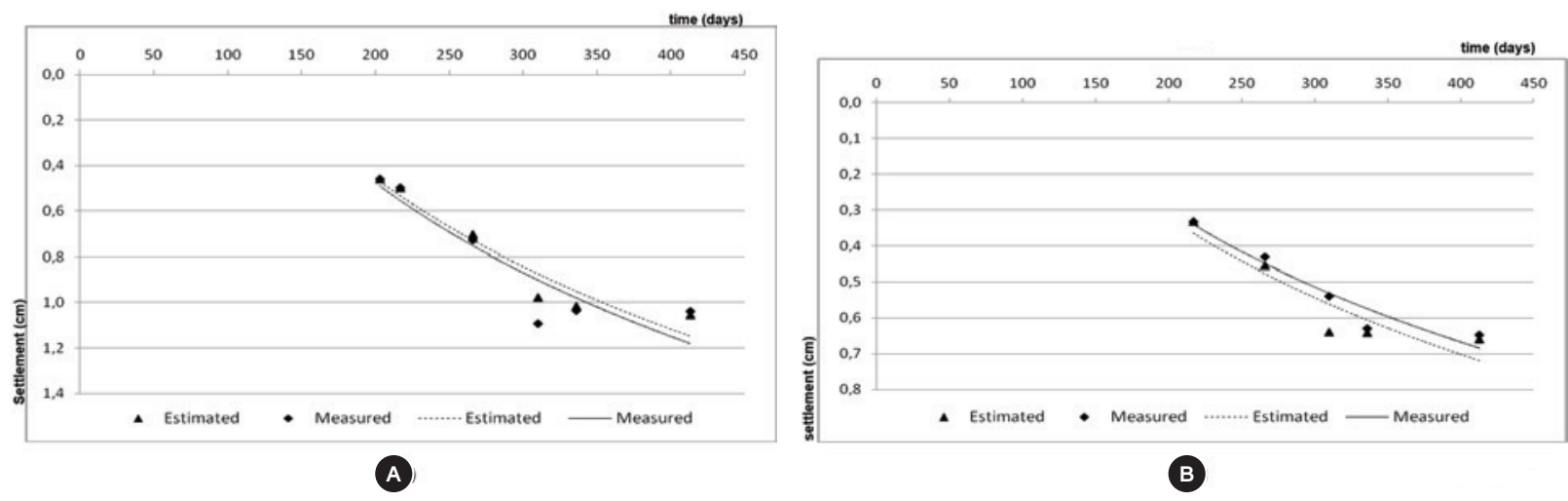

B

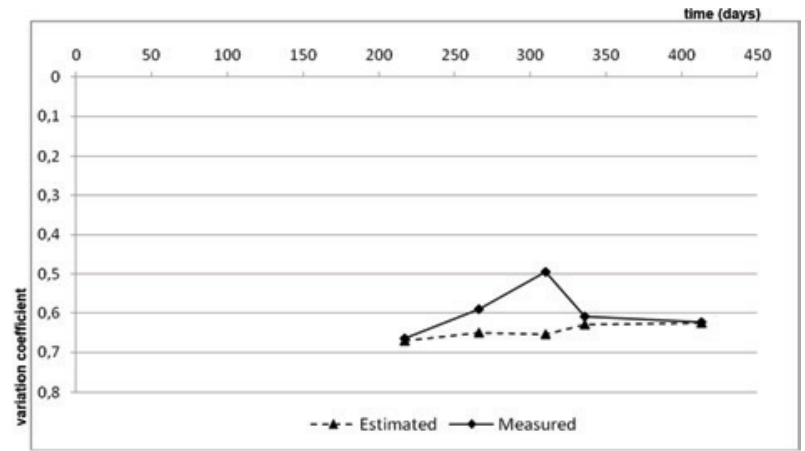

C

\section{Figure 9}

(a) Average, (b) Standard deviation and (c) Variation coefficient of the measured and calculated settlements

variation start in the same instant in Figure 9. For the estimated curve, the coefficient of variation reduced throughout the construction process, but very slowly. For the measured curve, the coefficient of variation presented higher amplitude of variation, possibly due to loss of some readings, as explained previously. It should be noted that, despite the differences that occurred during loading, the coefficient of variation were practically the same at the extremes of the instrumentation interval. That behavior has been observed as an overall pattern for similar instrumented constructions. The greater redistribution of loads and settlements uniformity usually takes place at the beginning of construction, when the rigidity of the structure increases during the construction of the first floors. Experimental observations demonstrate that the first floors are submitted to interaction effect in its most intensive extent. That is the reason why the presence of excessive settlements results in most intense structural damages precisely on the first floors. Unfortunately, the initial phase of the construction was not instrumented in the present case. As the present case study consists of a common residential building, with a very tight schedule, the authors were not allowed to change any planned events, despite all the support received from the construction team. The moment the instrumentation was allowed to start and the authors could begin the measurements, the construction had already advanced towards the fourth floor. It was not possible, therefore, to observe the interaction effect and estimate the coefficient of variation during the period it should undergo the more significant variation, in the first construction stages. The reduction in the coefficient of variation with the construction sequence was then observed, in the present case, but in a much more tenuous extent.

Referring to Figure 8, it can be observed that Gusmão Filho [5] already illustrated the most significant interaction effect and reduction in the settlement standard deviation in the first construction stages.

\subsection{Analysis considering concrete creep and shrinkage}

The previous analyses were useful to calibrate the model with respect to the soil characteristics and to allow the selection of an adequate stiffness coefficient $\mathrm{K}_{i}$ representative of the soil behavior for each columns support. The soil stiffness coefficient of the representative soil model $\mathrm{K}_{\mathrm{i}}$ was estimated as the ratio of load to estimated settlement, given in $\mathrm{kN} / \mathrm{m}$. The $\mathrm{K}_{\mathrm{i}}$ estimated by the calculated and the measured settlement presented a satisfactory agreement for the instrumented columns. Further analyses were based on stiffness coefficients upon updating the $\mathrm{K}_{\mathrm{i}}$ values corresponding to the $6^{\text {th }}$ constructive stage after the $3^{\text {rd }}$ iteration.

The soil structure interaction analysis including the concrete creep and shrinkage was conducted with the use of SAP2000 program, which is based on the formulations of the CEB-FIP Model Code [6]. For adoption of CEB recommendations, it is necessary to use empirical coefficients based on chosen parameters, geometric characteristics and mechanical properties of the structure, such as: the concrete compressive strength $\left(f_{c k}=35 \mathrm{MPa}\right)$, concrete elasticity 


\section{Figure 10}

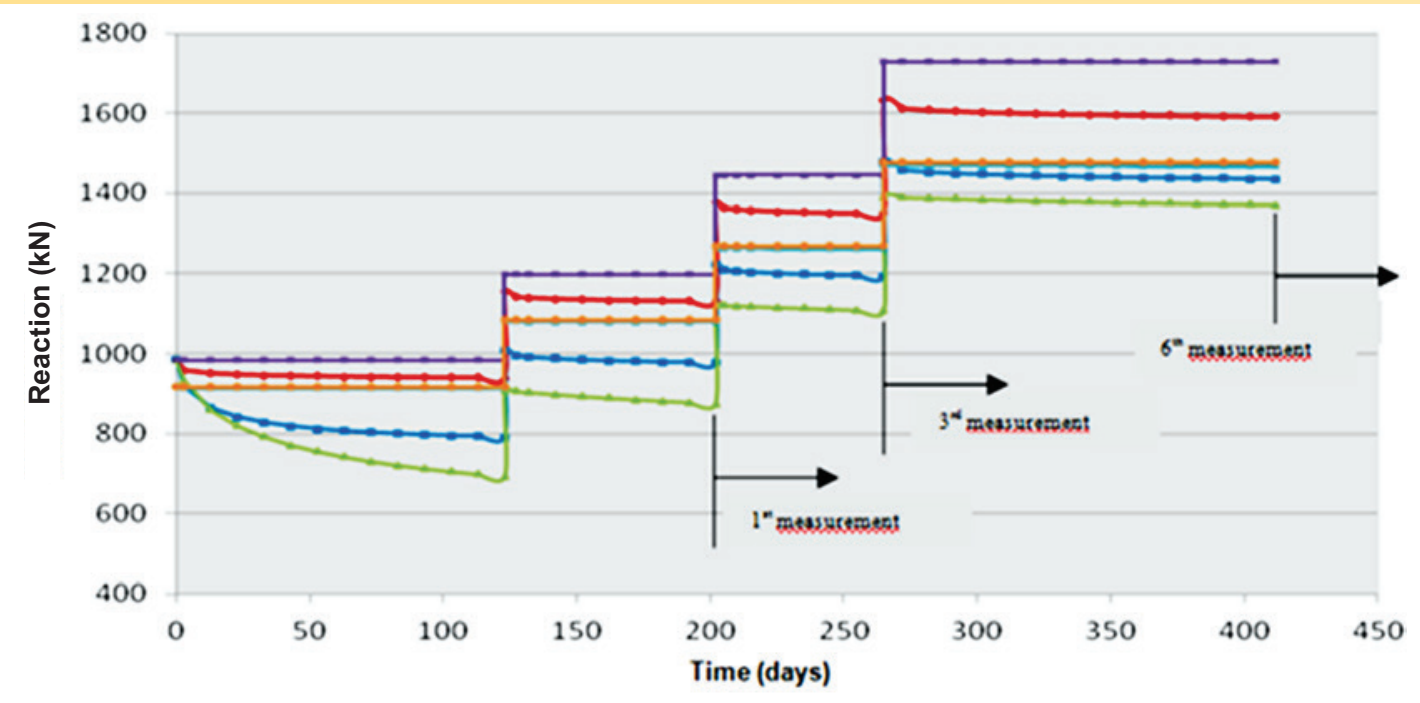

Compressive resistance with elapsed time after the initial of construction for column M5, for the 6 models

modulus $\left(E_{c i}=34 \times 10^{3} \mathrm{MPa}\right)$, cross section of components of the structure, relative humidity of the environment $(75 \%)$, age and duration of loading and type of cement $(0.25$, in the present analysis, corresponding to a normal hardening concrete). In regard to the age and duration of the loading, the construction stages according to in Table 1 were considered.

It is important to emphasize that for the analysis considering the concrete creep and shrinkage it was not necessary to consider all the construction stages, (1 to 6), listed in Table 1. The reason is the very small increase in loading between certain stages. In some cases, the intervals between stages were also very short.

In addition, a loading step before the start of the instrumentation interval (before the "zero" reading) was added. It was included in order to consider the load corresponding to the construction of the foundation, the underground, the partly-embedded floor, the ground floor and common use floor (PUC). This loading was added aiming at a better observation of the effects of the concrete creep and shrinkage.

Six models were conceived for the present case analyses in the course of time, as described below:

1) Structure resting on rigid supports;

2) Structure resting on elastic supports;

3) Structure resting on elastic supports and structural material subjected only to creep effect;

4) Structure resting on elastic supports and structural material subjected only to shrinkage effect;

5) Structure resting on elastic supports and structural material subjected to both creep and shrinkage effect;

6) Structure resting on rigid supports and structural material subjected to both creep and shrinkage effect.

Figures 10 and 11 show the compressive reactions on two typical columns, M5 and M22 with elapsed time after the beginning of

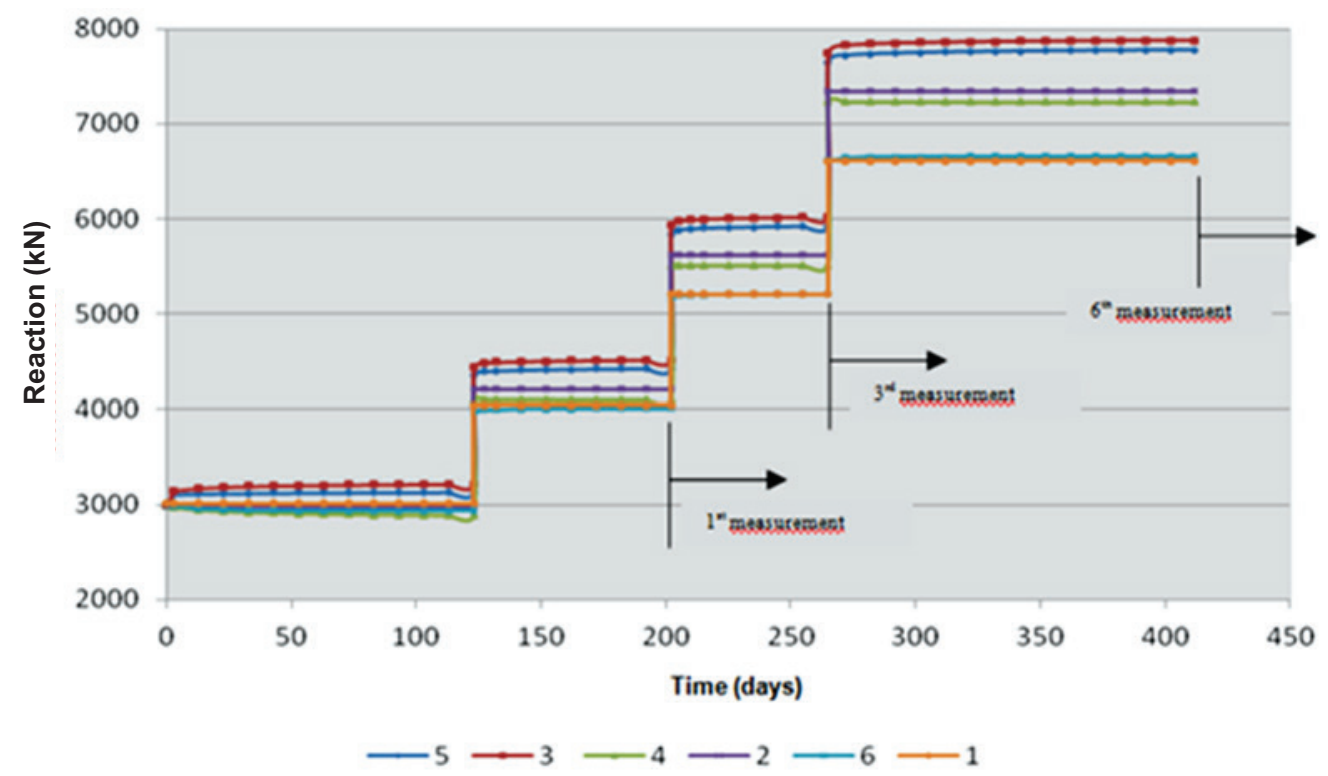

Figure 11

Compressive resistance with elapsed time after the initial of construction for column M22, for the 6 models 
construction for the models 1 to 6 listed above. In these figures, the successive steps characterize the loading stages.

Figure 10 shows the compressive reactions in column M5 resting on deep foundation (location shown in Figure 2 (a)). For this column, the upper bound load is relared to the structure on elastic supports and without the effect of creep and shrinkage (model 2 above), while the lower bound is related to the structure on elastic support and subjected only to the shrinkage effect (model 4). The effect of the creep resulted in the reduction of the compressive reaction in this column while the soil-structure interaction resulted in the reaction increase. The compressive reaction corresponding to model 5 , including the effect of creep and shrinkage, is situated between these two limits.

Figure 11 illustrates the compressive reactions in column M22, resting on a shallow foundation. In column M22 a redistribution of load caused the increase of the compressive reaction in all the steps of analysis.

The creep effect, in this column, resulted in increased compressive reaction for all stages, with the effect also increasing with elapsed time. A change in behavior was observed compared to the other columns analyzed in this research. In fact, soil structure interaction and creep in concrete components always presented effects in opposite directions.

The effect of the shrinkage indicated to be of minus relevance for this column, and caused a reduction in compressive loads. The authors observed, therefore, that in the great majority of the instrumented columns the effect of creep was contrary to the loading redistribution effect on soil structure interaction. The effect of the shrinkage was not significant. Gonçalves [7] also observed that the shrinkage effects were small and occurred mainly in the initial loading interval and more intensively in the region of high rigid support. From the interval of 140 days after the beginning of construction, the effects of shrinkage were also not significant.

Figure 12 shows the settlement distribution curves, after the $6^{\text {th }}$ construction stage, considering the soil-structure interaction and the effects of creep and shrinkage. The settlement distribution curves without consideration of creep and shrinkage effects were presented in Figure 7 (d). The effect of creep and shrinkage did not change the distribution of the settlement in plan for the case analyzed in this article. Their effect did not also modify the maximum settlement value, as observed when comparing Figure 7 (d) and Figure 12.

It can be concluded that for the case under study, the combined effect of creep and shrinkage did not contribute to a greater uniformity in the settlement distribution compared to the relevant effect of soil structure interaction.

Figure 13 shows the settlement distribution curves after the $6^{\text {th }}$ construction stage. In Figure 13 the estimated settlement prior to the existing loads at the beginning of the instrumentation was not considered. Figure 13 includes: (a) measured settlements, (b) calculated settlements considering soil-structure interaction, and (c) calculated settlements considering soil-structure interaction including creep and shrinkage effects.

A higher consistency can be observed when one compares the measured and the estimated settlement including only the soil structure interaction. In addition to the interaction, if the effect

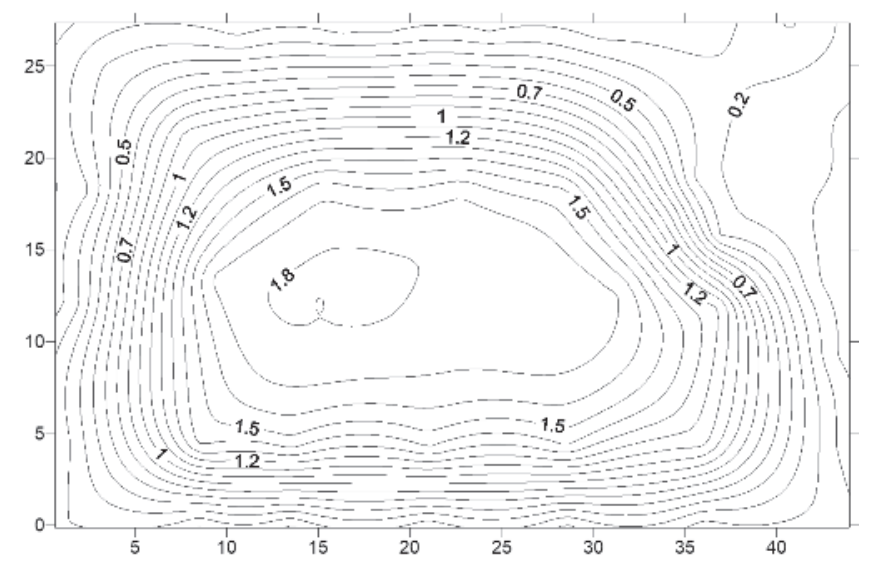

Figure 12

Settlement distribution for the $6^{\text {th }}$ construction stage, considering soil structure interaction and concrete creep and shrinkage effect, values in centimeters

of creep and shrinkage are also considered, a change in behavior can be observed in the central of the figure, with a much relevant uniformity of the settlements, higher than was actually observed in the measured curve. A difference in behavior can also be observed close to the corners of Figure 13, with a much sharply reduction in the curve when the creep and shrinkage effect are considered.

The main observation of this case study is that the effect of concrete creep and shrinkage in the numerical analysis points toward an evaluation in excess of its real significance when compared to the numerical analysis considering only the interaction effect, which presented a much closer approximate agreement to the instrumentation results.

\section{Conclusions}

The article presented the soil structure interaction analysis of a case study of a building founded on mixed foundations, with some columns resting on footings and others resting on steel driven piles. An extensive field instrumentation program was carried out with columns settlement and deformation measurements. The complete research results were presented by Rosa [1].

The article demonstrated the adequacy of the available numerical tools in reproducing structural behavior and group effect in soil settlement prediction. The ability to properly estimate an approximate value of soil compressibility model is also emphasized. This ability allows a consistent analyzes of soil structure interaction.

It was observed that the mean and standard deviation values of the measured settlements were found to be in very close agreement with the mean and standard deviation of the calculated settlements.

The multiple iterations analyses were observed to be very laborious and not justified in current cases, once do not result in significant differences in the settlement distribution behavior. The authors propose just one analyzes for soil structure interaction in current foundation reactions support. 

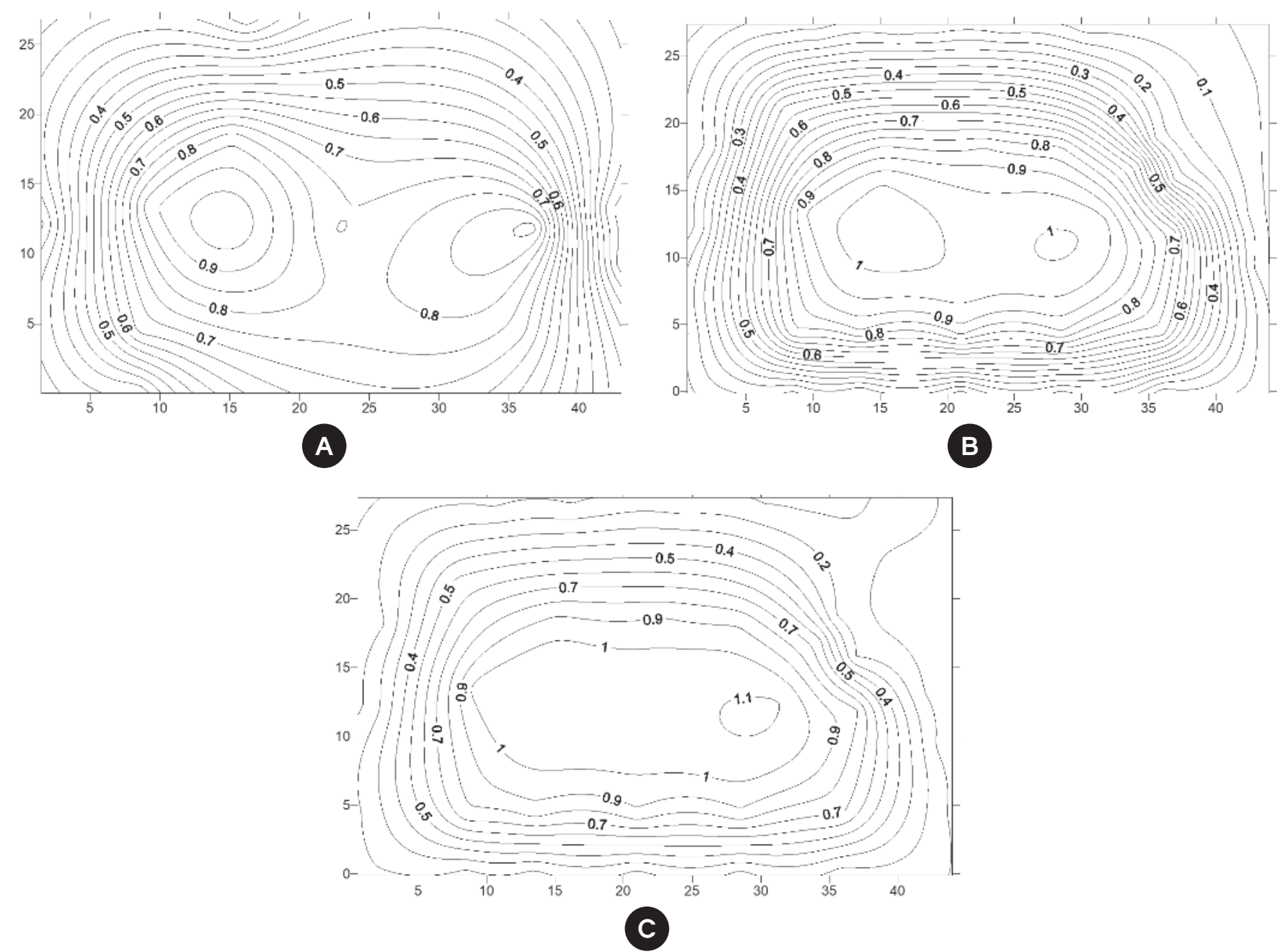

\section{Figure 13}

Settlement distribution curves for the $6^{\text {th }}$ stage: (a) measured; (b) estimated and (c) also considering concrete creep and shrinkage effect, values in centimeters

The authors observed that effect of concrete creep was contrary to the effect of soil structure interaction in relation to loading redistribution on columns foundation. When the column reaction increased, due to soil structure interaction, the effect of concrete creep caused the opposite effect. When column reaction increased, due to concrete creep, the effect of soil structure interaction caused a reduction in the column compressive reaction.

The concrete creep and shrinkage effect in the numerical analysis pointed out to an evaluation based on the CEB-FIP Model Code [6] recommendations in excess of its real significance when compared to the effect of the soil structure interaction alone.

\section{References}

[1] ROSA, L. M. P. Soil structure interaction: analysis considering creep in concrete (In Portuguese) Niterói, 2015, DSc Thesis - Civil Engineering Department, Fluminese Federal University, $204 \mathrm{p}$.

[2] ASSOCIAÇÃO BRASILEIRA DE NORMAS TÉCNICAS.
Foundations Design and Execution (In Portuguese). - NBR 6122, Rio de Janeiro, 2010.

[3] AOKI, N.; LOPES, F. R. Estimating stresses and settlements due to deep foundations by the Theory of Elasticity. Proceedings, $5^{\text {th }}$ Pan American CSMFE, Buenos Aires, v.1, p.377-386, 1975.

[4] CONDE DE FREITAS, A.; PACHECO, M.; DANZIGER, B. R. Estimating Young Module in Sands from the Normalized $N_{60}$ Blow Count. Soils and Rocks, vol. 35, n.1, 2012.

[5] GUSMÃO FILHO, J. Contribution to foundation practice: a experience from the city of Recife. Full professor These (In Portugueses), UFPE, Recife, 1995, 251 p.

[6] COMITÊ EURO-INTERNACIONAL DU BETON. CEB-FIP Model Code 1990, Design Code, Thomas Telford

[7] GONÇALVES, J.C. A Influência dos Recalques das Fundações no Comportamento de Edificações ao Longo do Tempo. Rio de Janeiro, 2010, Tese (doutorado), Engenharia Civil, Universidade Federal do Rio de Janeiro, COPPE/ UFRJ, 312 p. 